17,12

\title{
Влияние легирования атомами цезия и калия многостенных углеродных нанотрубок, выращенных в электрической дуге, на их эмиссионные характеристики
}

\author{
(C) К.Р. Израэльянц, А.П. Орлов, А.Б. Ормонт , Е.Г. Чиркова \\ Институт радиотехники и электроники им. В.А. Котельникова РАН, \\ Москва, Россия \\ ฯ E-mail: ormont.73@mail.ru
}

(Поступила в Редакцию 7 сентября 2016 г.)

\begin{abstract}
Исследовано влияние атомов цезия и калия, нанесенных на многостенные углеродные нанотрубки, выращенные в электрической дуге, на их эмиссионные характеристики. Обнаружено, что вольт-амперные характеристики автоэлектронной эмиссии образцов с многостенными углеродными нанотрубками данного типа, легированных цезием или калием, сохраняют свою прямолинейность в координатах Фаулера-Нордгейма в пределах нескольких порядков изменения эмиссионного тока. Показано, что нанесение атомов цезия и калия приводит к значительному увеличению эмиссионного тока и уменьшению работы выхода $\varphi$ исследуемых эмиттеров с многостенными нанотрубками. Установлено, что работа выхода уменьшается при оптимальной толщине покрытия атомами цезия до $\varphi \sim 3.1 \mathrm{eV}$, а в случае легирования калием - до $\varphi \sim 2.9 \mathrm{eV}$. Найдены оптимальные условия нанесения цезия и калия для достижения максимального эмиссионного тока.
\end{abstract}

DOI: $10.21883 / F T T .2017 .04 .44289 .344$

\section{1. Введение}

Углеродные нанотрубки представляют собой низковольтные автоэлектронные эмиттеры, поскольку характеризуются большим отношением длины к диаметру (aspect ratio), малым диаметром и острыми кончиками. Нанесение щелочных металлов на автоэлектронные эмиттеры на основе углеродных нанотрубок - как многостенных, так и одностенных - позволяет существенно улучшить их эмиссионные характеристики, т.е. увеличить эмиссионный ток и сделать эмиттеры еще более низковольтными (см., например, [1-4]). Влияние щелочных металлов на эмиссионные характеристики нанотрубок проявляется прежде всего в интеркаляции (внедрении) атомов щелочных металлов в нанотрубки. В случае многостенных нанотрубок (МСНТ) при наличии в их стенках дефектов существенное влияние, как указано в [1], оказывают процессы интеркаляции между слоями атомов углерода внутри нанотрубок. Для одностенных нанотрубок (ОСНТ), как показано в $[5,6]$, интеркаляция идет между пучками нанотрубок. При интеркаляции меняется плотность электронных состояний нанотрубок и уменьшается работа выхода.

Другой возможной причиной уменьшения работы выхода и увеличения автоэмиссионного тока может быть образование двойного электрического слоя из электронов и адсорбированных положительных ионов щелочных металлов. Такая модель развита для эмиттеров из тугоплавких металлов (см. обзор [7]) и может быть использована для случая нанесения атомов щелочных металлов на МСНТ [1].

Данных по исследованию влияния щелочных металлов на эмиссионные характеристики эмиттеров с углеродными нанотрубками (УНТ) в научной литературе мало.
Исследования подобного рода проводились в основном на ОСНТ [2,4]. Между тем эта информация важна при разработке технологических процессов легирования эмиттеров на основе УНТ щелочными металлами для улучшения их эмиссионных параметров и при оценке результатов применения разрабатываемых процессов. Для решения этой задачи важным шагом является исследование характеристик таких эмиттеров.

Ранее нами исследовалось влияние легирования цезием на эмиссионные характеристики МСНТ и ОСНТ, изготовленных методом химического осаждения углерода на различные подложки (ситалл, кварц) в присутствии катализаторов [1,2]. Наиболее ясная для понимания эмиссионных процессов картина была получена в случае влияния цезия на эмиссию из ОСНТ [2], поскольку на эмиссионных характеристиках ОСНТ в координатах Фаулера-Нордгейма после нанесения цезия всегда присутствовали прямолинейные участки. В случае МСНТ характеристики сложнее интерпретировать из-за наличия скачков тока и заметных отклонений от линейности.

Важным оставался вопрос о том, существуют ли среди различных МСНТ нанотрубки, эмиссионные вольтамперные характеристики которых в представлении Фаулера-Нордгейма после покрытия МСНТ щелочными металлами спрямлялись бы без скачков и отклонений от линейности, т.е. описывались теорией Фаулера-Нордгейма для проводников. В нашем распоряжении имелись МСНТ, выращенные иначе, чем исследованные в [1], - в электрической дуге - и имеющие иную пространственную структуру. Влияние легирования этих МСНТ щелочными металлами на их эмиссионные характеристики изучено не было.

В настоящей работе поставлена задача исследовать эмиссионные характеристики синтезированных в дуге 
МCHТ, легированных цезием и калием, а также сравнить особенности влияния цезия на характеристики поразному синтезированных МСНТ (в дуге и методом химического осаждения из газовой фазы (ХОГФ)).

\section{2. Методика эксперимента}

Исследования проводились на эмиттерах с МСНТ, выращенными в электрической дуге в гелии. В этом методе роста на отрицательном электроде образуется слой катодного депозита, состоящий из аморфного углерода с выросшими внутри него отдельными многостенными углеродными нанотрубками, выступающими на сломе депозита из его толщи.

Исследуемые образцы эмиттера представляли собой кусочки разломанного депозита размером в десятки микрометров, наклеенные проводящей серебряной пастой на никелевую пластинку размером $\sim 10 \times 9 \mathrm{~mm}$. На рис. 1 представлено микроизображение участка поверхности кусочка депозита на эмиттере, полученное с помощью растрового электронного микроскопа (РЭМ). Видны отдельные нанотрубки, торчащие из слоя аморфного углерода, выглядящего как темно-серые рыхлые образования. По оценкам длина нанотрубок равна 0.5-4 $\mu \mathrm{m}$. Диаметр нанотрубок, найденный из рис. 2 , где показаны нанотрубки при большем увеличении, лежит в диапазоне $10-20 \mathrm{~nm}$.

Эксперименты по измерению эмиссионных характеристик эмиттеров с нанесенным цезием и калием на эмиттеры после их предварительной очистки путем прогрева большим эмиссионным током проводились в камере универсальной сверхвысоковакуумной установки (УСУ-4) в вакууме $p \sim 5 \cdot 10^{-10}$ Torr. Во время отжига источников цезия и калия вакуум ухудшался до $p \sim 1 \cdot 10^{-8}$ Torr. Эмиттер вставлялся в держатель, закрепленный на универсальном манипуляторе, имеющем три поступательные и одну вращательную степени свободы. Манипулятор позволял отводить исследуемый эмиттер от анода, где он находился в режиме измерения автоэлектронной эмиссии, и подводить его к источнику цезия или калия на расстояние в несколько сантиметров. На фланце с токовыми вводами были смонтированы анод, представлявший собой стержень из нержавеющей стали, оканчивающийся полусферой диаметром $2 \mathrm{~mm}$, а также источники цезия и калия.

При нанесении цезия или калия соответствующий предварительно отожженный источник на основе хромата цезия или калия нагревался пропусканием через него электрического тока. При нагреве хромат щелочного металла разлагался с выделением свободных атомов цезия или калия. Последние попадали на образец, создавая на поверхности слой порядка суб- или моноатомного. Все нанесения слоев цезия и калия проводились в рабочем режиме источников при токах $I=2.6$ А.

При выполнении эмиссионных измерений исследуемый образец эмиттера располагался напротив анода. Расстояние $d$ между анодом и образцом составляло

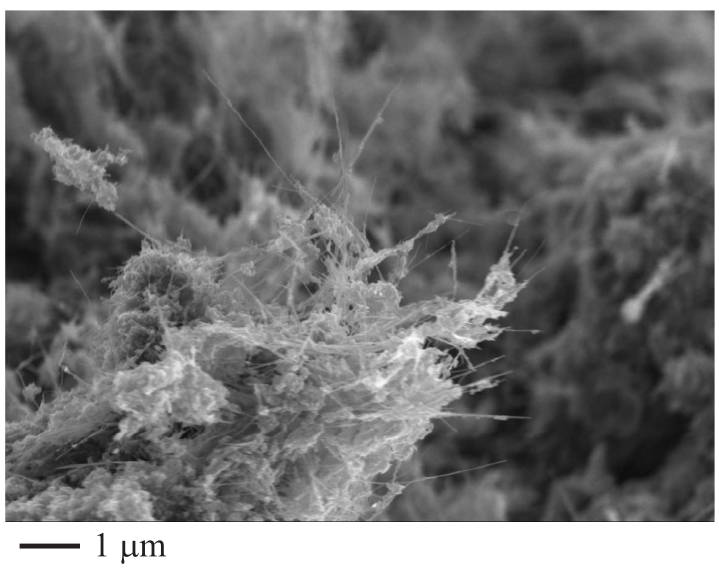

Рис. 1. Полученное в РЭМ микроизображение участков поверхности эмиттера с МСНТ, торчащими из толщи катодного депозита, выращенного в электрической дуге.

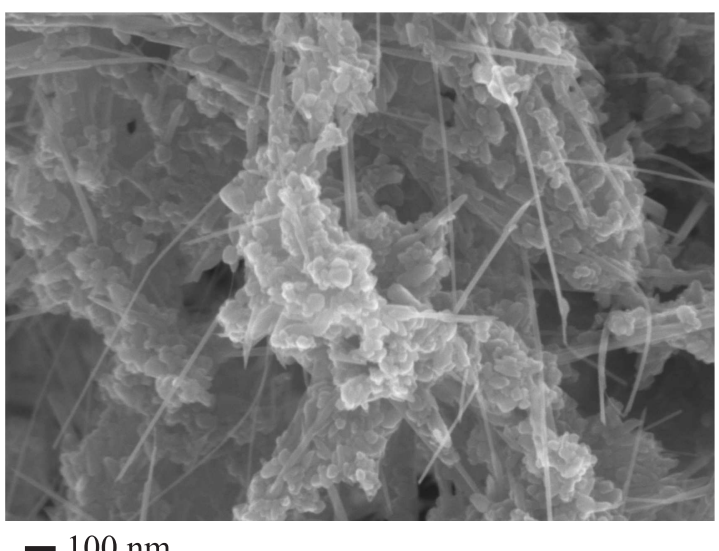

Рис. 2. Микроизображение нескольких МСНТ на эмиттере, полученное в РЭМ при большем, чем на рис. 1, увеличении.

около $400 \mu \mathrm{m}$ Оно измерялось по разности отсчетов лимба манипулятора в положении измерений эмиссии и в положении касания анодом образца (определялось по появлению электрического контакта между анодом и эмиттером).

Исследования вольт-амперных характеристик (BAX) автоэлектронной эмиссии проводились с помощью приборов фирмы Кейсли: программируемого источника высокого напряжения (Keithley 248), пикоамперметра (Keithley 6485) с персональным компьютером с адаптером интерфейса IEEE-488 системы GPIB с программным обеспечением. Для управления указанными приборами была модернизирована программа, созданная на базе программного пакета Test Point фирмы CEC.

Все эксперименты начинались с очистки исследуемого образца прогревом эмиссионным током в десятки микроампер в течение нескольких минут. После очистки и остывания в сверхвысоком вакууме проводились измерения вольт-амперных эмиссионных характеристик. Сравнивая ВАХ, полученные на разных этапах эксперимента, можно было судить о качестве очистки. 
Перед проведением эмиссионных экспериментов с нанесением цезия или калия одновременно с очисткой производилась тренировка эмиттера при токах эмиссии до $50 \mu \mathrm{A}$ до получения стабильной и воспроизводимой BAX.

\section{3. Результаты экспериментов}

Суб- и моноатомные слои атомов цезия или калия наносились на очищенный образец. Нанесение производилось двумя путями: либо непрерывно в течение некоторого времени, либо несколько раз последовательно с перерывами для измерения эмиссионных характеристик эмиттера. Во втором случае очередной слой наносился на предыдущий. В ходе эксперимента производилось сравнение характеристик чистого образца и образца, покрытого одним или несколькими слоями цезия или калия.

Всего было выполнено две серии экспериментов с нанесением цезия и одна серия экспериментов с нанесением калия.

В первой серии экспериментов наносились слои цезия с различной поверхностной плотностью, определяемой временем нанесения $(60,120$ и $180 \mathrm{~s})$ на очищенный образец. После каждого нанесения атомов цезия и измерения соответствующих $\mathrm{BAX}$ образец очищался прогревом большим эмиссионным током. Во второй серии экспериментов нанесение цезия было выполнено путем трех последовательных нанесений одно на другое в течение $10 \mathrm{~s}$ каждое. Таким образом, суммарная плотность слоя цезия соответствовала времени нанесения, равному $30 \mathrm{~s}$, а образец при этом очищался только один раз перед первым нанесением цезия.

Нанесение калия в соответствующей серии экспериментов велось последовательно, слой за слоем, с полным временем нанесения 10, 30, 120, 300 s. В целом в экспериментах с цезием поверхностная плотность нанесенных атомов, пропорциональная времени нанесения, варьировалась таким образом, что отношение максимальной плотности к минимальной составляло 18 раз. В серии экспериментов с калием плотность нанесенных слоев атомов калия варьировалась в пределах 30 раз.

Разница в проведении экспериментов с цезием и калием была обусловлена тем, что цезий является более активным металлом, чем калий, и его длительное нанесение с промежуточными измерениями существенно увеличило бы время эксперимента, что могло бы исказить его результаты из-за возможной миграции или десорбции части атомов цезия в процессе измерений.

Автоэлектронные эмиссионные характеристики одного из образцов эмиттера - как предварительно очищенного, так и с четырьмя нанесенными после очистки слоями цезия разной поверхностной плотности - представлены на рис. 3 в координатах $\lg I=f\left(E_{\mathrm{av}}\right)(a)$ и в координатах Фаулера-Нордгейма $\lg \left(I / E_{\mathrm{av}}^{2}\right)=f\left(1 / E_{\mathrm{av}}\right)(b)$. Здесь $E_{\mathrm{av}}-$ среднее электрическое поле в зазоре
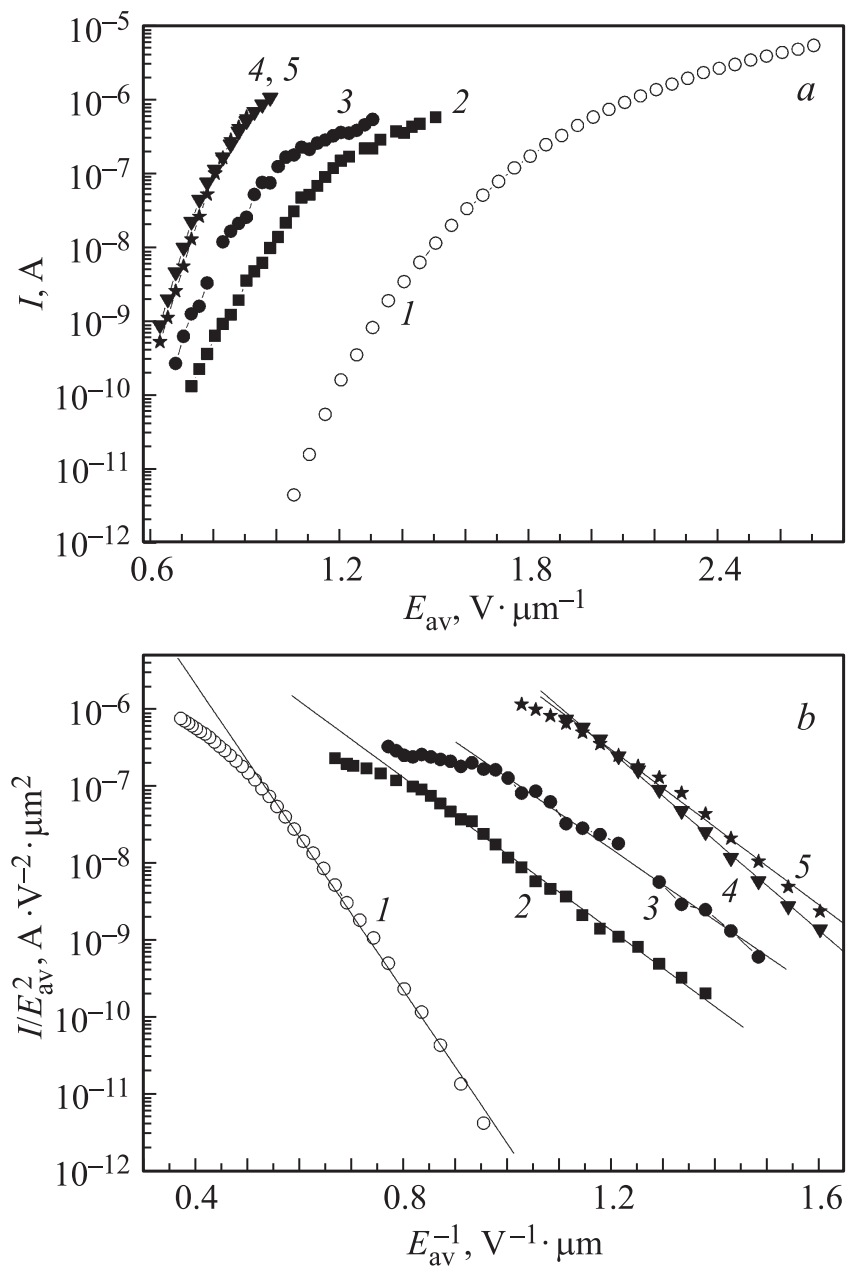

Рис. 3. ВАХ автоэлектронной эмиссии из образца эмиттера с МСНТ после первой очистки образца эмиссионным током (1), после двух серий последовательных нанесений атомов цезия в течение 10 (2) и $30 \mathrm{~s}$ (3) и после двух отдельных нанесений атомов цезия на очищенный образец с МСНТ в течение 60 (4) и $180 \mathrm{~s}(5) . a-$ характеристики в координатах $\lg I=f\left(E_{\mathrm{av}}\right)$. $b$ - те же характеристики, перестроенные в координатах Фаулера-Нордгейма $\lg \left(I / E_{\mathrm{av}}^{2}\right)=f\left(1 / E_{\mathrm{av}}\right)$.

анод-эмиттер, равное $E_{\mathrm{av}}=V / d$, где $V-$ приложенное напряжение, $d-$ расстояние анод-эмиттер. Как видно из рис. 3, $b$, характеристики в координатах Фаулера-Нордгейма являются прямолинейными как для чистого образца, так и для образцов после нанесения любого из слоев атомов цезия, т.е. соответствуют теории Фаулера-Нордгейма [8] для автоэлектронной эмиссии из проводников. Этой особенностью характеристики изучаемых в данной работе образцов отличаются от характеристик многостенных нанотрубок, исследованных в работе [1], которые имели скачки тока и отклонения от линейности в координатах Фаулера-Нордгейма.

Характеристики, измеренные после процедур чисток, свидетельствуют о том, что эмиттер хорошо очищается прогревом после многократного напыления цезия: кривые близки друг к другу и схожи с характеристикой 

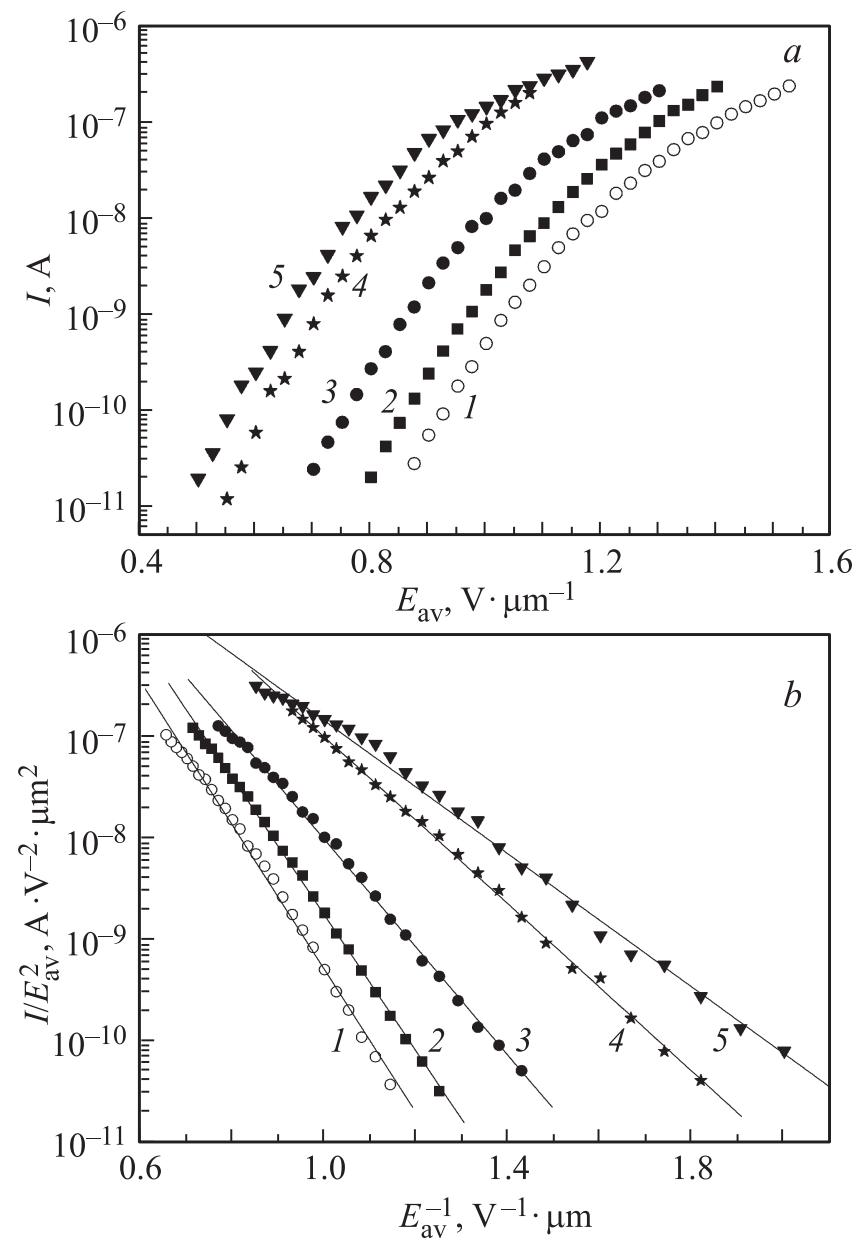

Рис. 4. ВАХ автоэлектронной эмиссии из образца с МСНТ после очистки его эмиссионным током (1), а также после четырех последовательных нанесений атомов калия в течение $10(2), 30(3), 120$ (4) и $300 \mathrm{~s}(5) . a-$ характеристики в координатах $\lg I=f\left(E_{\mathrm{av}}\right)$. $b-$ те же характеристики, перестроенные в координатах Фаулера-Нордгейма $\lg \left(I / E_{\text {av }}^{2}\right)=f\left(1 / E_{\text {av }}\right)$.

после первой чистки, сопровождаемой долгой выдержкой эмиттера в сверхвысоком вакууме. В координатах Фаулера-Нордгейма все эмиссионные характеристики близки к прямолинейным. Анализ результатов, изложенный в следующем разделе, для разных эмиссионных характеристик очищенных образцов в экспериментах с нанесением цезия дал незначительные отличия в наклонах спрямленных характеристик, связанных с важным параметром - коэффициентом усиления электрического поля. Этот параметр менялся в диапазоне значений 3000-3500.

Результаты измерений автоэлектронных характеристик одного из эмиттеров с МСНТ при его легировании тонкими слоями калия показаны на рис. 4, $a, b$. Представлены характеристики автоэлектронной эмиссии для одного из образцов: после предварительной очистки и после нанесения калия в течение $10,30,120,300 \mathrm{~s}$.

Из рис. 3, $a$ и 4, $a$ следует, что нанесение цезия или калия на эмиттер с МСНТ ведет к значительному умень- шению порогового электрического поля $E_{\mathrm{av}}-$ поля, при котором эмиссионный ток $I$ равен при покрытии цезием $\sim 10^{-9} \mathrm{~A}$, а при покрытии калием $I \sim 10^{-10} \mathrm{~A}$. При нанесении цезия пороговое поле $E_{\mathrm{av}}$ уменьшается от $E_{\mathrm{av}}=1.25$ до $0.63 \mathrm{~V} \cdot \mu \mathrm{m}^{-1}$. При нанесении калия соответствующее пороговое поле уменьшается от $E_{\mathrm{av}}=0.95$ до $0.55 \mathrm{~V} \cdot \mu \mathrm{m}^{-1}$.

\section{4. Анализ экспериментальных данных}

Процедура обработки и анализа полученных результатов была одинаковой для всех экспериментов. Вольтамперные характеристики анализировались на базе теории Фаулера-Нордгейма [8] подобно тому, как это делалось в [1]. Согласно этой теории, плотность тока автоэлектронной эмиссии $j$ связана с локальным электрическим полем $E$ вблизи поверхности эмиттера выражением

$$
j=\frac{1.5 \cdot 10^{-6} E^{2}}{\varphi} \exp \left(-\frac{6.8 \cdot 10^{7} \varphi^{3 / 2}}{E}\right) .
$$

Здесь $j$ выражена в А $\cdot \mathrm{cm}^{-2}, E-$ в $\mathrm{V} \cdot \mu \mathrm{m}^{-1}$, а работа выхода $\varphi-\mathrm{B} \mathrm{eV}$. Если перейти от плотности тока к току $I$ в соответствии с выражением $I=j S$, где $S$ - эмиссионная площадь, и от локального поля $E$ у поверхности эмиттера к среднему электрическому полю $E_{\mathrm{av}}$ в соответствии с формулой $E=\beta E_{\mathrm{av}}$, где $\beta-$ коэффициент усиления электрического поля, получим для эмиссионного тока

$$
I=\frac{1.5 \cdot 10^{-6} S \beta^{2} E_{\mathrm{av}}^{2}}{\varphi} \exp \left(-\frac{6.8 \cdot 10^{7} \varphi^{3 / 2}}{\beta E_{\mathrm{av}}}\right) .
$$

Здесь эмиссионная площадь эмиттера $S$ представляет собой сумму эмиссионных площадей $S_{i}$ отдельных эмитирующих нанотрубок. Анализируя формулу (2), можно получить выражения для основных параметров эмиттеров: $\beta$ и $S$. Если электрическое поле выражено в $\mathrm{V} \cdot \mu \mathrm{m}^{-1}$, а по оси ординат отложены десятичные логарифмы тока, как на рис. 3,a и 4, $a$, то можно получить следующие выражения:

$$
\begin{gathered}
\beta=\frac{2.83 \cdot 10^{3} \varphi^{3 / 2}}{B}, \\
S=\frac{\varphi}{1.5 \cdot 10^{-6} \beta^{2}} \cdot 10^{A-8} .
\end{gathered}
$$

Здесь $B$ - наклон ВАХ в координатах Фаулера-Нордгейма, $A$ - пересечение продолжения ВАХ с осью ординат в этих координатах. Величины $A$ и $B$ определялись путем линейной аппроксимации вольт-амперных характеристик в координатах Фаулера-Нордгейма.

Для определения величины $\beta$ по формуле (3) необходимо знать работу выхода $\varphi$. Мы предполагали, что для очищенных МСНТ работа выхода $\varphi=4.7 \mathrm{eV}$, такая же как для графита, и определили из формулы (3) величину $\beta$. Мы получили $\beta=3000-3200$ для первой серии 


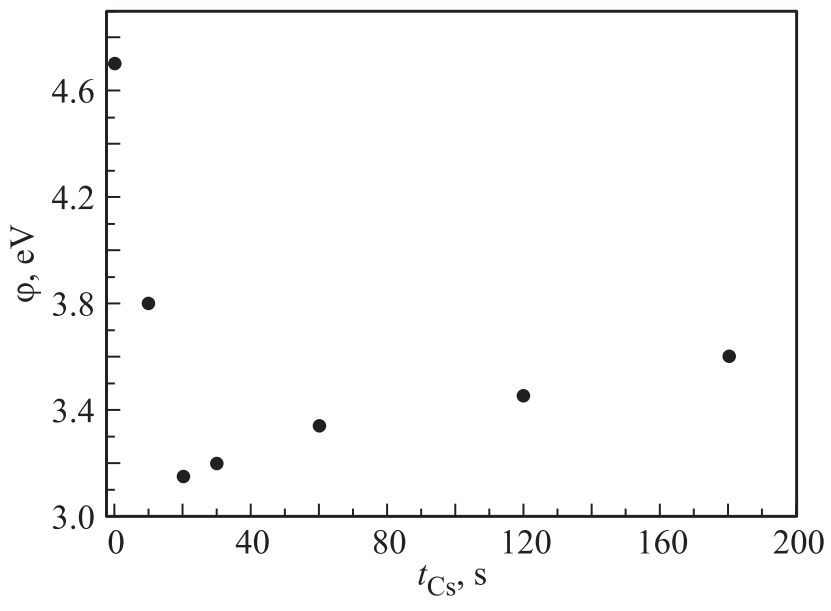

Рис. 5. Зависимость работы выхода МСНТ $\varphi$ от полного времени нанесения слоя (слоев) цезия $t_{\mathrm{Cs}}$ в диапазоне $10-180 \mathrm{~s}$ на предварительно очищенный эмиссионным током эмиттер c MCHT.

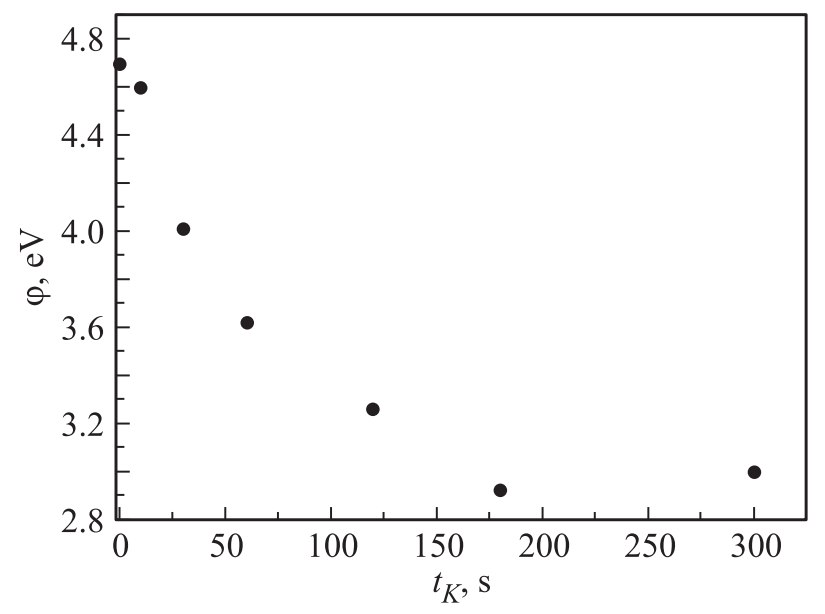

Рис. 6. Зависимость работы выхода МСНТ $\varphi$ от полного времени нанесения слоев калия $t_{\mathrm{K}}$ в диапазоне $10-300 \mathrm{~s}$ на очищенный эмиссионным током эмиттер с МСНТ.

экспериментов с нанесением цезия и $\beta=3200-3500$ для второй серии экспериментов. При анализе характеристик других образцов, на которые наносился калий, были получены величины $\beta \sim 4000$.

Далее, представляя формулу (3) в виде

$$
\varphi=\left(\frac{\beta B}{2.83 \cdot 10^{3}}\right)^{2 / 3},
$$

определяли работу выхода МСНТ с нанесенными атомами цезия или калия. При этом имелось в виду, что нанесение цезия или калия на МСНТ не могло изменить величину $\beta$, поскольку не меняло структуру нанотрубного слоя, а лишь увеличивало эмиссионный ток, сдвигало вольт-амперную характеристику в сторону меньших средних электрических полей и уменьшало работу выхода $\varphi$. Полученные значения приведены на рис. 5 и 6 в зависимости от времени нанесения щелочных металлов.

Анализ данных, полученных на основе эмиссионных $\mathrm{BAX}$, позволил найти эмиссионные площади с помощью формул (3), (5), (4). Эмиссионные площади для случаев нанесения цезия и калия приведены в табл. 1 и 2 . Результаты для цезия и калия сильно различаются. При нанесении цезия эмиссионные площади $S$ слегка уменьшаются от $S \sim 5 \cdot 10^{-11} \mathrm{~cm}^{2}$ для чистых образцов до $S \sim(1.5-2) \cdot 10^{-12} \mathrm{~cm}^{2}$ при малых временах нанесения (до $30 \mathrm{~s}$ ), а затем резко возрастают вплоть до $S \sim 10^{-8} \mathrm{~cm}^{2}$ при времени нанесения цезия, равном 180 s. При нанесении калия эмиссионные площади непрерывно уменьшаются от значения для чистых образцов $S \sim 4 \cdot 10^{-11}$ до $\sim 10^{-12} \mathrm{~cm}^{2}$ для времени нанесения $300 \mathrm{~s}$. Можно предположить, что изменение эмиссионных площадей отражает меняющееся число участвующих в автоэлектронной эмиссии МСНТ, и в этом смысле цезий как наиболее активный металл способствует созданию новых эмиссионных центров среди множества УНТ.

Изложенный подход к анализу автоэлектронных эмиссионных характеристик универсален и был нами применен, в частности, в работе [9] при анализе эмиссионных характеристик длинных нанонитей/нанотрубок.

Таким образом, нанесение атомов цезия на многостенные углеродные нанотрубки, полученные в электрической дуге, приводит к значительному увеличению эмиссионного тока и снижению работы выхода до $\varphi=3.1 \mathrm{eV}$ (c $\varphi=4.7 \mathrm{eV}$ для очищенного эмиттера). Это значение отличается от максимального изменения работы выхода для МСНТ в работе [1], где было достигнуто снижение работы выхода до $\varphi \sim 2.1-2.3 \mathrm{eV}$ в тех случаях, когда соответствующие характеристики в координатах Фаулера-Нордгейма были прямолинейными. В нашем

Таблица 1. Эмиссионные площади $S$ эмиттера с МСНТ при нанесении цезия

\begin{tabular}{c|c}
\hline Время нанесения $t, \mathrm{~s}$ & Эмиссионные площади $S, \mathrm{~cm}^{2}$ \\
\hline Очищенный эмиттер & $5 \cdot 10^{-11}$ \\
10 & $1.5 \cdot 10^{-11}$ \\
30 & $2 \cdot 10^{-11}$ \\
60 & $7 \cdot 10^{-9}$ \\
180 & $1 \cdot 10^{-8}$
\end{tabular}

Таблица 2. Эмиссионные площади $S$ эмиттера с МСНТ при нанесении калия

\begin{tabular}{c|c}
\hline Время нанесения $t, \mathrm{~s}$ & Эмиссионные площади $S, \mathrm{~cm}^{2}$ \\
\hline Очищенный эмиттер & $4 \cdot 10^{-11}$ \\
10 & $3.5 \cdot 10^{-11}$ \\
30 & $7.5 \cdot 10^{-12}$ \\
120 & $1.5 \cdot 10^{-12}$ \\
300 & $1 \cdot 10^{-12}$
\end{tabular}


случае достигнутое уменьшение работы выхода для МСНТ близко к значениям, полученным в работе [3] для покрытий цезием сравнимой толщины. В [3] работа выхода уменьшалась до 2.9-3.2 eV от исходного значения $5.0 \mathrm{eV}$ при слое цезия, нанесенном за $240 \mathrm{~s}$.

Минимальные значения работы выхода $\varphi$, как следует из рис. 5 , были получены при нанесении цезия в течение $20-30 \mathrm{~s}(\varphi=3.1-3.2 \mathrm{eV})$. Таким образом, существенное изменение работы выхода при нанесении цезия формируется при слоях цезия, нанесенных за короткое время (порядка нескольких десятков секунд).

В случае нанесения калия минимальное значение работы выхода $\varphi \sim 2.9 \mathrm{eV}$ (рис. 6) было получено при времени нанесения $180 \mathrm{~s}$.

B координатах Фаулера-Нордгейма характеристики различно легированных цезием образцов эмиттеров, а также характеристики очищенных эмиссионным током образцов спрямлялись в диапазоне эмиссионных токов шире чем $I \sim 3 \cdot 10^{-10}-1 \cdot 10^{-7} \mathrm{~A}$, калием - шире чем $I \sim 3 \cdot 10^{-11}-1 \cdot 10^{-7}$ A. Таким образом, автоэлектронная эмиссия из исследуемых структур, легированных цезием и калием, полностью подчиняется теории Фаулера-Нордгейма.

В результате проведенной работы были определены оптимальные условия нанесения цезия и калия для получения эмиттеров с высокими эмиссионными параметрами, при которых наблюдаются малые работы выхода. Они выражены через времена нанесения цезия и калия при токе протяженного источника цезия или калия $2.6 \mathrm{~A} \mathrm{c} \mathrm{расстояния} \mathrm{в} \mathrm{несколько} \mathrm{сантиметров} \mathrm{в}$ сверхвысоком рабочем вакууме $p \sim 5 \cdot 10^{-9}$ Torr.

\section{5. Заключение}

Проведенные исследования эмиттеров с МСНТ, полученными в электрической дуге, дали следующие результаты.

1. Все эмиссионные характеристики таких эмиттеров c МСНТ в координатах Фаулера-Нордгейма являются прямолинейными в широких интервалах токов (тричетыре порядка) как для очищенных образцов, так и для образцов, легированных цезием или калием. Эмиссионные характеристики исследованных в работе образцов, покрытых цезием, отличаются от характеристик ранее исследованных образцов с МСНТ, изготовленных методом ХОГФ (где после покрытия цезием измеренные последовательно характеристики демонстрировали отклонения от прямолинейности, скачки и нестабильность).

2. Показано, что нанесение атомов цезия на исследованные эмиттеры с МСНТ приводит к значительному увеличению эмиссионного тока и снижению работы выхода до $\varphi \sim 3.1 \mathrm{eV}$ по сравнению с $\varphi \sim 4.7 \mathrm{eV}$ для очищенного эмиттера. Нанесение атомов калия на эти МСНТ приводит, так же как в случае с цезием, к значительному увеличению эмиссионного тока и снижению работы выхода до $\varphi \sim 2.9 \mathrm{eV}$ по сравнению с $4.7 \mathrm{eV}$ для очищенного эмиттера.
3. Показано, что при легировании цезием среднее пороговое электрическое поле $E_{\mathrm{av}}$ исследованных МСНТ при токе эмиссии $I \sim 10^{-9}$ А снижается с $E_{\mathrm{av}} \sim 1.25 \mathrm{~V} \cdot \mu \mathrm{m}^{-1}$ для очищенных образцов до $E_{\text {av }} \sim 0.63 \mathrm{~V} \cdot \mu \mathrm{m}^{-1}$ для легированных образцов.

4. Эмиссионные площади при нанесениях цезия и калия на исследованные МСНТ сильно различаются. При нанесении цезия эмиссионные площади уменьшаются от значения $S \sim 5 \cdot 10^{-11} \mathrm{~cm}^{2}$ для чистых образцов до $\sim(1.5-2) \cdot 10^{-12} \mathrm{~cm}^{2}$ для малого времени нанесения (до $30 \mathrm{~s}$ ), а затем резко возрастают до $\sim 10^{-8} \mathrm{~cm}^{2}$ для времени нанесения $180 \mathrm{~s}$. При нанесении калия эмиссионные площади непрерывно уменьшаются от значения $S \sim 4 \cdot 10^{-11} \mathrm{~cm}^{2}$ для чистых образцов до значения $S \sim 10^{-12} \mathrm{~cm}^{2}$ для времени нанесения $300 \mathrm{~s}$.

5. Найдены условия нанесения цезия и калия на эмиттеры на основе исследованных МСНТ, позволяющие получать эмиттеры с улучшенными характеристиками. Эти условия включают в себя предварительную очистку эмиттеров путем отжига в течение нескольких минут-десятков минут большим эмиссионным током $(I \sim 50 \mu \mathrm{A})$ и последующее нанесение на очищенный образец цезия или калия. Для цезия оптимальное время нанесения в сверхвысоком вакууме $\sim 5 \cdot 10^{-10}$ Torr составляет $\sim 20-30 \mathrm{~s}$, для калия - около $180 \mathrm{~s}$.

В целом, как показано в настоящей работе, легирование (покрытие) цезием и калием улучшает параметры эмиттеров с МСНТ, выращенными в электрической дуге. Ранее не так явно это было продемонстрировано в нашей работе [1] и в работе [3] для покрытия цезием МСНТ других типов, в частности изготовленных химическим осаждением из газовой фазы. Улучшение параметров связано прежде всего с уменьшением работы выхода и проявляется в росте эмиссионных токов и снижении пороговых полей эмиссии.

Авторы благодарят А.Л. Мусатова за ценные замечания и полезные советы при проведении экспериментов и обсуждении их результатов.

\section{Список литературы}

[1] А.Л. Мусатов, К.Р. Израэльянц, Е.Г. Чиркова. ФТТ 56, 806 (2014).

[2] А.Л. Мусатов, К.Р. Израэльянц, Е.Г. Чиркова, А.В. Крестинин. ФТТ 53, 1428 (2011).

[3] D.H. Kim, H.R. Lee, M.W. Lee, J.H. Lee, Y.H. Song, J.G. Jee, S.Y. Lee. Chem. Phys. Lett. 355, 53 (2002).

[4] B. Ha, C.J. Lee. Appl. Phys. Lett. 90, 023108 (2007).

[5] O. Zhou, R.M. Fleming, D.W. Murphy, C.H. Chen, R.C. Haddon, A.P. Ramirez, S.H. Glarum. Science 263, 1744 (1994).

[6] S. Suzuki, M. Tomita. J. Appl. Phys. 79, 3739 (1996).

[7] Л.А. Большов, А.П. Напартович, А.Г. Наумовец, А.Г. Федоpyc. УФН 122, 125 (1977).

[8] R.H. Fowler, L.W. Nordheim. Proc. Roy. Soc. London A 119, 173 (1928).

[9] А.Б. Ормонт, К.Р. Израэльянц, А.Л. Мусатов. ФТТ 58, 191 (2016). 